\title{
De Coronéis a Bacharéis: reestruturação das elites e medicina em Sergipe (1840-1900)
}

\author{
From Coronéis to Bacharéis: The restructuring \\ of elites and Medicine in Sergipe (1840-1900)
}

Fernanda Rios Petrarca*

\section{Resumo}

$\mathrm{O}$ artigo examina os processos de recrutamento e as modalidades de inserção das elites médicas em Sergipe no século XIX. Para dar conta dessas questões analisamos as trajetórias desses profissionais considerando, por um lado, a história política do grupo familiar do qual faziam parte e, por outro, sua relação com o espaço econômico e político. As conclusões permitem apontar que as relações sociais de base familiar forneciam os critérios e as condições de recrutamento da elite médica. Além disso, o título de médico representou uma estratégia decisiva nas formas de reestruturação das elites políticas e econômicas, uma vez que por meio desse diploma as elites conservaram sua posição dominante e valorizaram seu capital social.

Palavras-chave: política, Sergipe, século XIX; medicina; família; elites.

\section{Abstract}

The article examines the processes of recruitment and forms of insertion of the medical elites in Sergipe in the nineteenth century. To do this, we analyzed the trajectories of these professionals considering, on the one hand, the political history of the family group they were members of, and on the other, their relationship with political and economic space. The conclusions permit the identification of which family based social relations provided the criteria and the conditions of recruitment to the medical elite. Moreover, the title of doctor represented a decisive strategy in the forms of restructuring political and economic elites, since through this degree the elites preserved their dominant position and valorized their social capital. Keywords: politics, Sergipe, Nineteenth century; medicine; family; elites.

A profissão médica tem sido tratada pela literatura sociológica sobre os universos profissionais como a atividade que mais conquistou poder e privilégio. Ao longo da sua história a medicina tomou para si o monopólio da cura e reivindicou, com sucesso, o poder de definir o que é doença e a forma como

* Universidade Federal de Sergipe (UFS). Aracaju, SE, Brasil. f.petrarca@uol.com.br ${ }^{1}$ 
tratá-la, bem como o direito exclusivo de exercer o ofício. Com um projeto profissional bem-sucedido, com notável aliança com o Estado e com os grupos socialmente dominantes, a medicina negociou o exercício profissional e conquistou prestígio, legitimidade e status.

Os estudos, por um lado, dedicaram-se a compreender a história da medicina, do conhecimento e da organização médica centrando nas descobertas, nas concepções de doença e na formação de um saber próprio (Borges, 1992; Chalhoub, 1996; Luz, 1996; Santos Neto, 2001). Por outro lado, enfatizaram as condições de organização e formação de uma cultura profissional (Hughes, 1956; Becker, 1961) voltando-se para o exame dos processos que levaram a medicina a ocupar uma posição dominante no mercado da cura (Freidson, 2009). Apesar das divergências entre essas abordagens que se situam entre a historiografia e a sociologia das profissões, elas têm em comum a ênfase internalista do ofício, ignorando a influência das condições externas na sua consolidação.

Este artigo, entretanto, pretende demonstrar a importância dos fatores externos na formação de um espaço privilegiado de atuação profissional. Tomando como ponto de partida um conjunto de estudos que abordam as interseções entre profissão e política, ${ }^{2}$ examina-se, a partir do caso de Sergipe, o papel dos grupos familiares dirigentes na formação de uma elite médica. De modo mais específico, o problema central consiste em compreender como a medicina compôs os sofisticados mecanismos de reestruturação e de renovação das elites regionais. Um dos pressupostos mais gerais, presentes neste tipo de estudo, está relacionado ao exame das elites tendo como recorte as disputas entre os agentes para ocupação de posições dominantes e a sua relação com os recursos disponíveis e os princípios de legitimação de suas práticas (Bourdieu, 1989; Canedo, 2011; Charle, 2006; Coradini, 2008; Saint-Martin, 1980).

Tal problematização envolveu, pelo menos, duas definições fundamentais. Primeiro, tomamos como objeto empírico os médicos que ocuparam posições-chave no espaço da medicina em Sergipe e que, portanto, estavam situados no topo de "estruturas de autoridade ou de distribuição de recursos", atuando nos postos mais almejados e disputados do ofício. Isso significa afirmar que não estamos analisando todos os médicos do período considerado, mas aqueles que se destacaram pelas posições ocupadas. ${ }^{3}$ Segundo, definimos como recorte temporal a segunda metade do século XIX, uma vez que tal período se caracteriza pelo nascimento e gênese do ofício médico em Sergipe. ${ }^{4}$ Em termos metodológicos, para darmos conta das questões propostas, partimos dos percursos biográficos e das trajetórias sociais dos médicos e sua relação com o processo de recrutamento e atuação política das elites. As principais fontes de dados mobilizadas foram: 
biografias, dicionários biográficos, material histórico (jornais, discursos) e material bibliográfico (monografias, teses, dissertações e livros).

Um elemento importante para compreensão desse objeto é que, nesse contexto, a medicina clínica era um ofício secundário e não desfrutava de prestígio social e valorização profissional num mercado privado de cura. ${ }^{5}$ As enfermidades eram vistas como problemas políticos, e como tal exigiam a intervenção do Estado. Doenças epidêmicas, dentre elas a febre amarela, a dengue, a malária e a cólera, eram com frequência associadas às más condições de higiene e aos meios insalubres e, por isso, tornava-se fundamental a disciplinarização da população. Assim, as principais formas de exercício da medicina estavam associadas à medicina pública e à política, seja na ocupação de cargos de saúde e higiene, seja na forma de cargos políticos eletivos (deputado, senador, governador). Além de ser desempenhado por um pequeno grupo com posição econômica elevada, o ofício dependia das relações de base familiar como critério de seleção e recrutamento para a ocupação de tais cargos. Em situações regionais onde se situavam as faculdades de medicina e as associações profissionais, a consagração médica dependeu, além da política, da cátedra e da participação em entidades de classe (Coradini, 1996). Nos demais, como é o caso de Sergipe, a atuação estava associada, exclusivamente, às disputas num mercado de cargos públicos e políticos.

Nessas condições, o controle dos postos almejados pelos médicos era inseparável dos alinhamentos políticos que resultavam dos acordos entre a oligarquia agrária. Tais acordos dependiam da parentela que - como princípio de estratificação social organizada com base na rede de parentes e afins - conduzia ao sistema de distribuição dos cargos. Como todos os postos eram controlados por esses agrupamentos políticos locais "de base familiar", a medicina não pode ser compreendida senão dentro desse sistema de relações. $\mathrm{O}$ uso da expressão "de base familiar" segue os padrões estabelecidos por Lewin (1993) para evitar aproximações com a noção “domínio familiar”, esta última caracterizada pelo recrutamento político exclusivamente mediante parentesco. Nessa linha, o termo "parentela" nos permite, analiticamente, compreender a rede de parentes e amigos de um chefe político que constituía sua base fundamental de apoio e domínio. A hipótese central deste artigo, portanto, reside na noção de parentela como estrutura de dominação e hierarquização social à qual a medicina estava submetida, nesse contexto.

Para dar conta dessas questões, demonstraremos, num primeiro momento, em que medida os diplomas passaram a integrar o sistema de parentela, diversificando o recrutamento das elites políticas e permitindo compreender 
o acesso aos postos médicos. A principal fonte de dados consiste em material bibliográfico e historiográfico. Num segundo momento, apresentaremos parte de um banco de dados construído sobre o perfil sociográfico e a composição social da "elite" médica em Sergipe, a partir do qual podemos identificar as origens sociais e as principais formas de atuação desses médicos no século XIX. E por fim, com base nos percursos biográficos e na análise dos itinerários sociais de alguns casos exemplares, examinaremos a relação entre a estrutura dos alinhamentos políticos e familiares em Sergipe e a medicina. O principal elemento nesse último tópico é o papel do título de médico na diversificação da vida política e das alianças entre famílias. Uma das principais contribuições do caso sergipano é possibilitar a compreensão da lógica que une as complexas relações entre medicina, famílias e política.

\section{AS RECONVERSÕES DA OLIGARQUIA AGRÁRIA: O SISTEMA DE PARENTELA E A “CONVERSÃo DE TÍtUlos ACADÊMICOS”}

A relação entre bacharelismo e oligarquia agrária já foi amplamente debatida pela historiografia brasileira (Holanda, 2016; Freyre, 2003; Carvalho, 2007). Contudo, poucos são os trabalhos que demonstram a dinâmica da estrutura de hierarquização e dominação e como o título de bacharel compôs as estratégias dos grupos dominantes. Nessa direção, tomamos o sistema de parentela como a chave da organização social e política e um idioma para compreender as relações e os espaços profissionais do século XIX até as primeiras décadas do século XX. Trata-se de uma dinâmica marcada pelo domínio dos proprietários rurais - que eram chefes políticos locais denominados também de coronéis - e baseada nos arranjos, muitas vezes incertos e instáveis, entre famílias e afins (aliados políticos, afilhados, amigos). A "política de parentela" que emerge desse sistema representa a força desses chefes políticos locais e seus aliados nos agrupamentos políticos e sua influência nas demais esferas da vida social (Leal, 1949; Levine, 2006; Pang, 1979; Queiroz, 1976). As alianças constituídas eram múltiplas e, em geral, envolviam desde parentes consanguíneos e parentes por afinidades a aliados políticos e laços de compadrio. Isso resultou numa fórmula bastante conhecida: "parentes + afins" (Candido, 1951; Queiroz, 2006).

Esse sistema não é uma característica exclusiva de Sergipe, mas representa o desenvolvimento da política e a expansão do Estado brasileiro tendo como núcleo o município. As dificuldades enfrentadas por Portugal para dominar e 
povoar o país, dada sua dimensão continental, conduziram ao incentivo do poder e autonomia dos senhores rurais. A consequente independência do país colocou aos proprietários rurais a necessidade de enviar representantes às câmaras municipais e, em seguida, às câmaras provinciais (Queiroz, 1976). Nas economias regionais menos ricas e nos estados politicamente dependentes de outras regiões, como é o caso de Sergipe, o controle dessas famílias era quase absoluto. Essa situação trouxe pelo menos duas implicações importantes.

Primeiro, eram as lutas entre proprietários rurais que marcavam a disputa pela posse e controle dos cargos. Uma luta pautada pelo confronto e desentendimento constante entre as lideranças, pela emergência de dissidências, facções e grupos opositores. Nessa disputa a posse dos títulos nobiliárquicos, como o baronato, representava um recurso importante e uma forma de se distinguir nas disputas políticas locais. O próprio baronato sergipano é um exemplo disso. É, sobretudo, após 1840 que esses títulos são distribuídos entre os grupos dominantes na província. Constituído por proprietários rurais, donos de engenho, os barões sergipanos, em geral, não possuíam formação universitária e eram destacados políticos locais e proprietários de terra (Albuquerque, 2002). Foram as gerações seguintes, dos filhos dos barões, que diante da intensa concorrência que se travou entre os grupos, contribuíram para diversificar as estratégias de sua composição por meio do investimento em títulos universitários. Esse fenômeno, que denominamos "conversão de títulos", representou uma forma específica de mobilização da formação acadêmica.

Segundo, com a criação das Assembleias Provinciais eles conservaram o poder sobre o município e enviaram às câmaras provinciais membros da família, e/ou da parentela, com alguma formação acadêmica. A necessidade de manter o controle sobre o município e ao mesmo tempo expandir o poder em outras esferas levou os grupos a terem de enviar aliados ou parentes para disputar em outros níveis (estaduais e federais). É nessa direção que os títulos passaram a compor as lutas por distinção entre as parentelas, convertendo-se ora em recurso para diferenciar e hierarquizar os grupos, ora em trunfo para ocupar novas posições políticas. Aos poucos, com a crescente urbanização da sociedade, a ampliação da máquina estatal, a expansão dos serviços públicos e a criação de novos postos, eles se tornaram um dos canais de poder desses chefes políticos locais (Adorno, 1988; Blondel, 1957; Leal, 1949; Lewin, 1993; Queiroz, 1976).

A mobilização dos títulos acadêmicos para fins políticos demonstrou a capacidade de renovação e diversificação desse sistema e representou uma importante estratégia das famílias para colocar seus membros nos cargos mais 
prestigiosos, garantindo sua posição política e econômica. Os filhos formados, em geral nos cursos de bacharel em direito ou medicina, representavam as parentelas nas câmaras provinciais e, ao seguirem a carreira política de senador ${ }^{6}$ ou deputado, faziam a conexão entre o município, base principal do poder do coronel, e o sistema político nacional.

Mas esses bacharéis possuíam trunfos importantes que foram acionados na conversão dos títulos para a carreira na política. Um desses trunfos foram as redes estabelecidas na faculdade. Por terem de estudar fora dos limites do seu município e estado, eles já viviam em espaço urbano diversificado, no qual estabeleciam suas próprias redes de relações e as conectavam com suas bases familiares. Tal situação lhes permitiu tirar alguma vantagem, uma vez que a conexão entre as redes formadas nas academias e as bases familiares ampliou e cristalizou vínculos que transcendiam as alianças locais. Outro trunfo importante foi a própria formação acadêmica que estimulava os bacharéis a colocar seus conhecimentos para ocupação de cargos estatais. No caso do direito, a oratória e o conhecimento jurídico fortaleceram os investimentos políticos; já no caso da medicina a necessidade do controle das epidemias permitiu aos médicos colocar seu saber voltado à saúde pública e à ocupação de cargos em delegacias de higiene, comissões de vacinação e departamentos de saúde.

O processo de "conversão de títulos" permitiu sair de uma situação de "grupo de base familiar", cuja conexão social era o parentesco, para uma situação de "rede de base familiar", como aponta Lewin (1993). Enquanto o "grupo" correspondia a uma parentela (amigos de longa data definidos como quase-parentes e parentes consanguíneos ou recrutados pelo casamento), a rede interligava facções individuais. As redes se tornaram mais ilimitadas e permitiram conectar politicamente os diferentes níveis - local, estadual e federal. Segundo Linda Lewin, esse processo foi longo e associado a uma crescente valorização dos "afins" para os grupos familiares, ou seja, daqueles que vinham de fora e que foram adquirindo relativa importância nas disputas por posições políticas. Nesse contexto, os laços de sangue ou aqueles obtidos pelo casamento não asseguravam mais a posição na política e não eram garantia de confiança. Uma alternativa que se abriu foi a amizade política baseada nos alinhamentos familiares, estendendo assim a rede e conectando o município ao nível federal. As redes dependiam cada vez mais de membros não parentes para conectar o nível local ao poder político federal.

Nesse quadro os bacharéis se tornaram importantes mediadores entre o Executivo e o Legislativo, integrando a estrutura coronelística pelo casamento ou por laços constitutivos da parentela. Aos poucos, eles se apropriaram da 
abertura do mercado político e monopolizaram os postos estatais (Adorno, 1988; Lewin, 1993). Em Sergipe, apesar da proximidade com a Faculdade de Direito de Pernambuco, por um lado, e com a Faculdade de Medicina da Bahia, por outro, o número de formados era bastante escasso até a primeira metade do século XIX. É somente depois desse período que se observa um investimento na formação dos filhos. Além disso, a proporção dos formados em Direito em Olinda (PE) se tornava superior à dos formados em medicina.

Os títulos acadêmicos compuseram os movimentos de recomposição das elites, desempenhando papel fundamental na renovação dos dirigentes regionais. Se até a primeira metade do século XIX eles seguiam o modelo coronelístico, a partir da segunda metade se voltam para fora dos limites do município formando-se bacharéis. Esse processo de expansão dos recursos políticos promoveu um deslocamento no espaço social, e alguns recursos tenderam a perder sua valorização, como no caso das relações centradas exclusivamente nos chefes políticos locais.

Contudo, essa capacidade de renovação das elites dependeu também das condições específicas de organização econômica e política. Os chefes políticos sergipanos tinham como principal atividade econômica, durante o século XIX, o açúcar, por meio dos engenhos. Comparados aos dos estados vizinhos Bahia e Pernambuco -, os engenhos de Sergipe eram de pequeno e médio porte, ocupando uma área territorial de pequena extensão, o que permitia a existência de vários engenhos em um mesmo município. Isso gerava esta situação: para dominar um município, as famílias precisaram fazer alianças. Esse tipo de oligarquia que se formou não era exercido, portanto, por uma única família, mas por diversas famílias conectadas pelo casamento ou por vínculos políticos e de amizade, que dominavam com base em alianças, fortalecendo a relação entre parentes e afins. Estruturadas a partir das divergências e dos conflitos pelo controle e escoamento da produção do açúcar, tais grupos familiares aliados controlavam todos os postos locais, como médico, juiz, tabelião e até mesmo párocos. O confronto entre proprietários de engenho dividiu o estado em duas principais regiões produtoras de açúcar que cobriam $2 / 3$ do seu território: região do Cotinguiba e Vaza Barris. Em cada uma dessas regiões havia o domínio de um conjunto de chefes políticos locais, cada qual tentando controlar suas alianças num delicado equilíbrio.

Alguns elementos contribuíram para que a organização desses grupos ocorresse por meio da aliança entre várias famílias. Primeiro, o caráter fragmentário da terra, caracterizado pela pequena propriedade, ocasionado, muitas vezes, pela extensão das famílias que em geral possuíam mais de cinco filhos. 
A consequência foi a transformação em pequenas propriedades de engenho espalhadas em diversos municípios, à medida que os filhos casavam. Em geral, as famílias possuíam propriedades que abrangiam quatro ou cinco municípios, o que tornava a aliança com outros proprietários indispensável no controle da região. Segundo, a grande quantidade de engenhos em uma área que cobria 2/3 do estado (Dantas, 2004; 2009) elevou a concorrência entre essas famílias, reforçando a necessidade das alianças e tornando-as indispensáveis.

Nesse sentido, a figura do "supercoronel", como observado em outras situações regionais (Levine, 2006; Love, 2006; Pang, 1979), não se destacou em Sergipe, uma vez que os chefes locais alcançaram no máximo a dominação sobre alguns poucos municípios e dificilmente conseguiam controlá-los por inteiro. A influência política e econômica sobre determinada região, vila ou município dependia do equilíbrio, muito delicado, entre quatro ou cinco famílias. Seu controle era bastante fragmentado e instável e estava sujeito ao acordo com outros chefes locais de famílias diferenciadas e com interesses muitas vezes divergentes, sobretudo quando se tratava de indicar lideranças para sucessão ou para ocupação de cargos e postos locais.

Assim, o coronel representava uma liderança que estava no topo de uma parentela, ligado por laços de sangue, matrimoniais, compadrio, amizade ou alianças políticas. Quanto mais conexões e vínculos um chefe político possuísse com diferentes outros grupos e famílias, mais importante ele se tornava na dominação de determinada área. Ao mesmo tempo, essa ampliação das relações se tornava fonte de tensão e enfraquecia o seu grupo de origem e as relações firmadas a partir dele, gerando dissidências e facções.

Essa estrutura baseada na forte concorrência entre as parentelas e nas suas alianças dependeu da mobilização de um conjunto de recursos que permitiu a distinção e hierarquização entre os grupos. A concentração de poder de uma parentela passou a depender, cada vez mais, dos bacharéis aptos a mobilizar seus saberes profissionais para ocupação de cargos municipais, estaduais e federais. E é dentro desse sistema de disputa entre grupos que o médico se situava, uma vez que estava nas mãos das parentelas o controle do município e de todos os cargos envolvidos (juiz, inspetor, promotor, delegado, professor e vigário). Mais do que isso, o bacharel representava a possibilidade de expansão das redes de relações. As estratégias de conversão dos títulos acadêmicos em trunfos no espaço político foram cruciais para a manutenção desse sistema. Nessa linha, o acúmulo de diferentes tipos de recursos garantiu à oligarquia agrária o controle político, diversificando a estrutura de capitais do grupo. 


\section{A ELITE MÉDiCA NO SÉCULO XX: HOMOGÊNEA, AGRÁRIA E POLÍTICA}

Para análise do processo de recrutamento e da composição social das elites médicas no século XIX, construímos um banco de dados que permitiu analisar uma população de 143 bacharéis que se destacaram em Sergipe, em posições de prestígio e poder, entre 1840 e 1900. Na falta de uma instituição que nos fornecesse dados para a delimitação da elite médica, recorremos ao Dicionário Médico Biográfico (Santana, 2009) e ao Dicionário Biobibliográfico de Sergipe (Guaraná, 1925) como as principais publicações regionais de autoconsagração do grupo profissional. Além disso, codificamos em torno de 54 variáveis, as quais nos permitiram medir: origem geográfica, formação profissional, espaços de atuação profissional, homenagens recebidas e origens sociais.

No que diz respeito às origens geográficas podemos perceber que $91,6 \%$ dos médicos que ocupavam posições dirigentes entre 1840 e 1899 eram de Sergipe, e $86 \%$ deles do interior do estado. A característica principal é a de uma elite médica endógena e majoritariamente rural e agrária, nesse período. Esses dados têm relação direta com a atividade econômica dos pais e com o contexto político, uma vez que tal atividade se concentrava na zona rural, com os engenhos de produção de açúcar. Além disso, o interior do estado nesse contexto exerceu papel político importante, uma vez que as câmaras municipais tinham poder de voz e de representação no Legislativo.

No tocante às formações profissionais, nesse período, 79\% dos médicos se formaram na Bahia, apenas 17,5\% no Rio de Janeiro e 3,5\% no exterior (França, Bélgica e Coimbra). Esse dado é particularmente interessante quando associado à constituição do espaço de formação médica. No século XIX existiam três cursos de formação na área médica, um dos quais na Bahia (1808), outro na cidade do Rio de Janeiro (também datando de 1808) e, apenas na última década do século, no Rio Grande do Sul (em 1898). Era para essas faculdades - ou para as do exterior - que os aspirantes a médicos se destinavam.

Nesse contexto, as faculdades em geral estavam preocupadas com o controle das grandes epidemias que assolavam a população, como a febre amarela e a cólera morbo, voltando-se para a higiene pública, o controle sanitário e a polícia médica (disciplinarização da população). As discussões científicas conduziam os médicos a colocar seus ofícios a serviço da política e da formação do Estado, ocupando espaços nos hospitais e nas delegacias e comissões de higiene. ${ }^{7}$ Nessa direção a Faculdade de Medicina da Bahia teve papel de destaque não só nas discussões sobre a expansão da febre amarela e o papel do Estado no controle da epidemia (Edler, 1998; 2002), mas também como centro 
intelectual e irradiador de debates. Dentre os temas priorizados pelos médicos na defesa de suas teses destacavam-se as doenças infecciosas e a saúde pública (Bochner; Moreira, 2015). Seus professores tiveram forte atuação política, participando ativamente das contestações que marcam essa geração e ocupando cargos públicos.

Portanto, a concentração de formados na Faculdade de Medicina da Bahia trouxe como consequência a homogeneidade em termos de treinamento, unificando a elite médica. A exposição desses profissionais a um conjunto de debates comuns contribuiu para consolidar um tipo específico de habilidade e conhecimento, associado a uma cultura geral e política e por isso de fácil reconversão para ocupação de postos na burocracia pública. Isso se tornou poderoso elemento de unificação ideológica dessa elite. Além disso, a proximidade geográfica com a Bahia favorecia a formação das redes de contatos entre estudantes.

No que diz respeito às atividades desempenhadas pelos médicos nesse contexto, podemos afirmar, com base nos dados, que 65\% ocupavam cargos de direção, seja em órgãos públicos direcionados à saúde, seja na política de maneira mais abrangente. Nessa conjuntura, os médicos que atuavam em Sergipe não viviam da medicina clínica e passavam a maior parte do tempo em postos políticos administrativos ou como chefes políticos locais, voltando-se para uma vida política, uma vez que o mercado de serviços médicos e a clínica como atividade principal eram praticamente inexistentes. O próprio saber médico era mobilizado, essencialmente, para ocupar posições na esfera estatal e para se posicionar diante de problemas sociais ligados, sobretudo, às más condições de higiene da população. $\mathrm{O}$ seu poder devia-se à imbricada relação entre o sistema de parentela e a formação médica. Em outras situações regionais onde existiam as Faculdades de Medicina e as Associações Profissionais a consagração médica se dava pela atuação como catedrático e membro da Academia Imperial de Medicina, além dos vínculos e cargos políticos ocupados. Como estamos lidando com um estado em que tais espaços não existiam, a consagração médica se dava quase que exclusivamente por meio da política. É nesse sentido que o estudo do caso de Sergipe pode revelar as condições de realização da medicina em situações históricas específicas.

O exame das homenagens recebidas também constituiu elemento importante da caracterização e diferenciação interna dessa elite médica. Podemos perceber, no banco de dados, que $18 \%$ dos médicos que ocuparam posições dirigentes no período considerado receberam homenagens. Desse conjunto, $70 \%$ receberam homenagens de instituições políticas, os demais se subdividem 
em homenagens de instituições profissionais, literárias e religiosas. A configuração dessas homenagens está diretamente relacionada à configuração do ofício médico clínico, nesse contexto, como ofício secundário. Portanto, era para a vida política que esses profissionais se voltavam. As gerações de médicos do final do século XIX coincidem com as elites sociais, econômicas e políticas e, por esse motivo, se distinguem internamente pela consagração política.

Já com relação às origens sociais, tomamos a profissão do pai como uma das principais variáveis. Com isso observamos que $51 \%$ dos médicos - para os quais conseguimos dados biográficos sobre origens sociais - formados no século XIX eram filhos de militares, seguidos de $12 \%$ de políticos e $14 \%$ de médicos. Nesse contexto, proprietários de engenho recebiam também títulos e honrarias militares, o que os tornava ao mesmo tempo fazendeiros, políticos e militares. Além disso, o termo coronel, que em nosso banco classificamos como militar, representava nesse contexto um poder político e econômico importante. No início do século XIX o termo coronel representava uma posição associada à Guarda Nacional. Contudo, com a extinção desse título, os coronéis continuaram se atribuindo essa denominação que passou a representar um tipo de poder local baseado na barganha entre governo e oligarquias locais, das quais os coronéis eram os principais representantes.

Como lidamos com informações produzidas por outras fontes (dicionário biográfico, homenagens, obras biográficas) o registro "coronel" aparecia de forma variada, ora caracterizado como militar, ora como fazendeiro, ora como coronel. Esse registro dificultou a caracterização da atividade profissional dos pais dos médicos, nesse contexto. Em função disso, optamos pelo registro genérico "militar".

Como a posição profissional do pai e sua respectiva escolaridade se tornaram um indicador bastante frágil de apreensão das origens, recorremos à análise da trajetória de alguns grupos familiares para ter um melhor quadro a respeito das origens sociais. No final do século XIX a medicina, como vimos, representou uma importante estratégia de reprodução e manutenção da condição de elite. Em geral, as famílias que investiam na educação universitária dos filhos, em Sergipe, os encaminhavam para estudar medicina na Bahia ou direito em Recife, este último priorizado em função do próprio caráter polivalente do título.

Dentre as famílias que se destacaram na medicina estão os Rollemberg, os Leite, os Rabello Leite e os Costa Dória. Tais famílias eram descendentes de colonizadores portugueses, assim como pertencentes à oligarquia agrária (proprietária de engenho e produtora de cana-de-açúcar) e com forte atuação na 
política municipal e estatal. Isso nos permitiu caracterizar as trajetórias médicas que transcorreram na segunda metade do século XIX como determinadas pela "política de parentelas" e formadas por redes de base familiar como a principal forma de acesso à medicina.

Trata-se portanto, nessas condições, de uma elite profissional homogênea, uma vez que era recrutada pelas famílias dirigentes, formada e treinada pelas mesmas faculdades e voltada à resolução de problemas de saúde pública e não a serviços privados num mercado de cura. Além disso, era eminentemente rural e agrária. Entretanto, apesar de se constituir como elite unitária - em termos de perfil social e formas de treinamento e atuação -, era ao mesmo tempo segmentada e fragmentada, em função da sua distribuição no sistema de parentela. A forte concorrência no interior das parentelas e sua consequente subdivisão contribuíram para que as elites médicas se organizassem conforme essa estrutura.

\section{CONDIÇÕES DE RECRUTAMENTO E SELEÇÃO:}

\section{PARENTELAS E ALINHAMENTOS POLÍTICOS}

O ofício de médico em Sergipe estava associado ao desenvolvimento de uma carreira política que começava com os postos de delegado de higiene, passando pelo de deputado até chegar a senador e presidente da província. A estrutura estava organizada em torno não só de alguns hospitais (ao total quatro) que funcionavam como casas de isolamento, mas também dos departamentos de saúde e de higiene do estado, cuja atuação central era nomear comissões durante as grandes epidemias e prestar socorro as vítimas em momentos de surtos. A medicina clínica privada era praticamente inexistente, uma vez que a sobrevivência médica com base nela não constituía a regra. Em geral, os jovens médicos ao retornarem para suas cidades de origem montavam consultório que durava por no máximo 2 anos e partiam para a carreira política. Isso está associado a pelo menos dois movimentos fundamentais. Primeiro, a concorrência dos médicos com outras formas tradicionais de cura, como a reza, a pajelança e a benzedura. Segundo, a formação e o treinamento médico nesse contexto estavam direcionados à atuação política nos seus municípios de origem. Procuraremos aqui destacar a relação entre as trajetórias dos principais médicos, os grupos políticos e familiares e as parentelas aos quais estavam vinculados. 
Os primeiros médicos a atuar em território sergipano estavam vinculados à parentela de Almeida Boto. Em meados da década de 1840 o grupo de Sebastião Almeida Boto liderava as forças políticas locais, compondo o grupo dos conservadores, em oposição aos liberais, estes últimos representados pelos Araújo Maciel e Travassos. Segundo Oliveira Vianna (1999), Almeida Boto constitui a primeira oligarquia brasileira. Sua ascensão é, em parte, resultado das alianças com base nas relações familiares e vínculos políticos que soube bem constituir. Suas propriedades resultam, de um lado, da herança dos pais - colonizadores portugueses que ocupavam a área da região do Cotinguiba - e, de outro, do casamento com uma viúva proprietária de três engenhos e irmã de José de Barros Pimentel, importante coronel e chefe político local (Dantas, 2009). De início, ele mobiliza os principais recursos da época para consolidar seu poder econômico e político: herança e matrimônio.

Os conflitos políticos e a instabilidade das alianças políticas da parentela de Almeida Boto conduziram à emergência de dissidências no interior do Partido Conservador, dando origem a novas lideranças que se opunham. É nesses alinhamentos políticos e familiares que se situam dois importantes nomes da política nesse contexto. O primeiro foi Manoel Joaquim Fernandes de Barros, médico sergipano formado na universidade de Estrasburgo, que exerceu a política como presidente da província de 1835 a 1836. Considerado o homem mais ilustrado da província em seu tempo, era aliado de outro chefe político local concorrente de Almeida Boto na disputa pelo controle do escoamento do açúcar. Em função do seu casamento com a viúva do cunhado de Boto (José de Barros Pimentel), liga-se a ele pelos laços familiares, e as tensões atingem proporções violentas. As brigas por herança e os litígios familiares levaram ao assassinato de Fernandes de Barros, o que contribuiu para desestabilizar as alianças políticas de Almeida Boto.

O segundo médico também vinculado à parentela de Almeida Boto foi José de Barros Pimentel, enteado de Fernandes de Barros e sobrinho de Boto. Formou-se em Paris em 1842 e era filho do seu homônimo. No ano seguinte à formatura assumiu o cargo de secretário do governo de Sergipe, no momento em que a província era presidida por Almeida Boto. Representou Sergipe em cinco legislaturas pelo Partido Liberal, que tinha como liderança Antonio Dias Coelho (Barão de Estância), indicado por Almeida Boto. Manteve-se na política até a morte, no final do século XIX, ocupando cargos nas legislaturas e em outros órgãos como a fundação e direção do Banco da Bahia. Tornou-se um dos políticos mais proeminentes da corrente liberal. As famílias Pimentel, Barros e Coelho, unidas por laços de matrimônio e aliança política, permanecem como 
algumas das que mais se destacaram nos cargos de deputados provinciais e senadores na segunda metade do século XIX. Nesse contexto, o número de formados em medicina não era expressivo e o estado era praticamente representado pelos chefes políticos locais que, na luta para manter suas propriedades e poder, mantinham um intenso conflito.

É principalmente a partir da década de 1860 que o título acadêmico se torna um recurso importante e valorizado no interior das parentelas. Isso está associado primeiro, como já foi dito, à concorrência entre as parentelas; segundo, à ampliação de postos políticos e ao aumento da máquina estatal, o que conduziu à necessidade crescente dos bacharéis. Nessas condições podemos ainda citar o caso do médico Gonçalo de Faro Rollemberg, que se destacou na política regional como senador. A família Rollemberg estabeleceu alianças com diferentes chefes políticos locais ao longo do século XIX e tem seus vínculos políticos consolidados ao longo da década de 1860. A família caracterizou-se pelos investimentos em casamentos dentro (tios, sobrinhas, primos) e fora da parentela, possibilitando aliança com outros grupos. Um dos marcos para a presença marcante dos Rollemberg na política é o casamento entre Maria José Rollemberg (viúva proprietária de três engenhos na região do Cotinguiba) com João Gomes de Mello (Barão de Maroim). Este último, compadre e amigo de Almeida Boto, ao casar-se com a referida viúva ampliou sua propriedade, abrangendo os municípios de Rosário do Catete, Siriri, Japaratuba e Santo Amaro das Brotas. Sua incursão na política começa pelas alianças com Almeida Boto, mas o casamento e a conquista do título de Barão de Maroim lhe permitiram novos vínculos, essenciais para sua eleição a deputado provincial em 1847. Assim, ele se torna uma das principais lideranças do Vale do Cotinguiba. Os enteados do Barão de Maroim, dentre eles o Barão de Japaratuba (avô do médico Gonçalo de Faro Rollemberg) unem-se pelo matrimônio com outras famílias de chefes políticos locais, como os Prado, Sampaio e Madureira. Contudo, essa relação entre diferentes famílias na liderança de uma parentela era difícil de administrar e exigia habilidade política. As tensões, sobretudo por herança, conduziam a divisões e à emergência de dissidências que, por sua vez, contribuíram para a perda da liderança e sua fragmentação.

É nessa configuração que se integra o médico Gonçalo de Faro Rollemberg, nascido em 1860 no Engenho Maria Teles em Maruim - neto, pelo lado materno, do Barão de Japaratuba (enteado de João Gomes de Mello - Barão de Maroim), e pelo lado paterno, de um Capitão Mor de Sergipe. Seus pais eram primos, o que contribuiu para manter a família Rollemberg como umas das principais lideranças dos engenhos na região do Cotinguiba. Herdeiro do 
Engenho do Topo, casou-se em 1884 com Aurélia Almeida Dias Coelho Melo, herdeira do Engenho Escurial e filha do Barão de Estância (Antonio Dias Coelho), um dos maiores produtores de açúcar da região de Estância. Assim, ele uniu a produção de açúcar do vale do Cotinguiba, do qual era um dos proprietários com seu Engenho do Topo, à produção de açúcar da região do Vaza-Barris por meio da relação com o sogro, proprietário do engenho Escurial.

Iniciou o curso de medicina na Bahia e o concluiu no Rio de Janeiro, em 1881. Ao retornar dos estudos para sua terra natal, assumiu o cargo de delegado de higiene em Japaratuba e no mesmo ano foi eleito deputado provincial. $\mathrm{O}$ cargo de delegado de higiene representava, em geral, o primeiro degrau de uma carreira política. Mas foi por intermédio do sogro - Antônio Dias Coelho - que Gonçalo intensificou sua participação na vida política, tornando-se importante chefe político em Japaratuba, município onde construiu sua base. Mais adiante sucedeu o sogro na liderança do Partido Liberal elegendo-se vice-presidente da província e, logo em seguida, presidente. A liderança ocorria, de um lado, por alianças locais e, de outro, pelas alianças regionais com dirigentes dos partidos. No caso de Gonçalo, no âmbito local liderou a oposição aos irmãos Maciel em Japaratuba aliando-se a outros chefes; no âmbito regional, alianças com o sogro - presidente do Partido Liberal - e com o tio - aliado político do sogro e um dos mais "expressivos líderes do Partido Liberal" (Dantas, 2009) - lhe deram as condições de liderança política.

Outro elemento constitutivo das alianças regionais eram as alianças estabelecidas fora de Sergipe com políticos federais que poderiam dar suporte nas lutas locais. Essas alianças eram formadas durante o exercício dos mandatos de deputado federal ou senador ou durante a realização dos cursos de graduação. No caso de Gonçalo, no Senado da República fez amizade e estreitou laços com o senador Nilo Peçanha, de quem obteve apoio em diferentes situações. Uma delas foi o movimento de Reação Republicana que representava os ideais de Nilo Peçanha e que em Sergipe teve como chefe local, eleito por Nilo, Gonçalo Rollemberg (Nascimento, 2007).

Assim como muitos dos seus contemporâneos, Gonçalo exercia a medicina clínica eventualmente, chegando a produzir alguns artigos sobre hepatite e anestesia. Seu investimento concentrou-se na administração do engenho da família e na política, como deputado, senador e, posteriormente, presidente do estado (hoje, governador). Dando curso a sua carreira política, torna-se vice-presidente do estado e presidente em 1894. 
Três outros médicos ainda se tornariam presidentes da província no final do século XIX e início do século XX: João Vieira Leite, José Rodrigues da Costa Dória e Felisbelo Freire. O primeiro nasceu em 1867 no Engenho São Félix, neto do coronel João José de Oliveira Leite (Barão do Timbó) e irmão do também médico Berilo Leite. O Engenho São Félix se destacou na região como um dos principais ao manter alianças familiares e políticas com outros engenhos da região, como o Engenho Antas, da família Costa Carvalho. Inicialmente o engenho constituiu-se com a união das famílias Souza Vieira e Leite por meio do matrimônio entre Joaquina Hermelina Vieira e João José de Oliveira Leite (Barão do Timbó). Ambos eram viúvos, com seis filhos cada. As alianças matrimoniais múltiplas caracterizaram os Leite de Estância, como o casamento de três filhos de Joaquina com três filhos de João Leite, o que contribuiu para fechar os Leite em si mesmos. Filho de uma dessas alianças múltiplas, João Vieira Leite se formou na Faculdade de Medicina da Bahia em 1890 e iniciou sua carreira atuando em consultório, na cidade de Estância. Contudo, foi em cargos políticos que se destacou. De um lado, cargos eletivos como o de deputado estadual, exercido por duas legislaturas, seguido de presidente da Assembleia e intendente municipal nos anos de 1897 e 1898 e presidente de Sergipe. De outro lado, cargos públicos como o de delegado de polícia, delegado de higiene e diretor do hospital no município de Estância. Tais cargos foram proporcionados tanto pelas alianças endógenas da família quanto pelos vínculos estabelecidos por meio do jornal A Razão, de propriedade de Augusto Ramos Gomes, seu cunhado. Ele compõe, portanto, a parentela dos "Leite de Estância”, para a qual o jornalismo desempenhou importante papel de influência e força política.

O segundo, José Rodrigues da Costa Dória, era opositor político de Gonçalo Rollemberg e vinculado à parentela de Olímpio Campos e do grupo dos chamados "cabaús". ${ }^{8}$ Membro de uma família de coronéis e chefes políticos de Propriá, formou-se em 1882 pela faculdade de medicina da Bahia e exerceu a clínica médica por 2 anos na cidade de Laranjeiras, centro político e econômico de Sergipe. Em seguida, foi aprovado em concurso para vaga de catedrático da Faculdade de Medicina da Bahia, onde atuou de 1885 até 1891. Com a criação da Faculdade de Direito do estado da Bahia, tornou-se também catedrático de medicina legal no recém-criado curso (Abreu, 2001; Santana, 2009). Seu retorno a Sergipe se dá para ocupar o cargo de deputado federal pelo estado em 1897. Sua entrada na política é marcada, de um lado, pelos acordos locais a que seu grupo familiar pertencia; de outro, pelas redes que foi capaz 
de construir no período acadêmico e pelos acordos no âmbito federal em que soube investir.

Sua passagem pela Faculdade de Medicina da Bahia lhe permitiu formar suas próprias redes de relações sociais e as conectar com seu estado de origem. Dessas amizades e laços construídos resultaram convites para ocupação de cargos e apoios políticos. Como exemplo, podemos citar a relação estabelecida com Severino Vieira e Luis Tarquino, respectivamente político do Partido Conservador baiano e empresário, a qual resultou no convite para atuar como conselheiro municipal de Salvador (Saad, 2013). Outra importante relação foi a firmada com Manuel Vitorino, político baiano e catedrático da Faculdade de Medicina da Bahia, com quem pôde contar no momento da sua candidatura para deputado federal por Sergipe, uma vez que Vitorino era vice-presidente da República nessa ocasião. Tais vínculos lhe permitiram dedicar-se exclusivamente à política, como deputado federal por quatro legislaturas e como presidente do estado em 1908. É dentro do espaço acadêmico e da política que seu investimento ocorre. Por um lado, como catedrático em medicina legal pôde circular com facilidade entre a medicina, o direito, o jornalismo e a política, participando dos debates que marcavam a intelectualidade desse contexto. Isso lhe rendeu o reconhecimento nacional como um dos primeiros responsáveis por estudar e publicar os efeitos da maconha na população africana, tendo apresentado seu trabalho em congressos internacionais no momento e se integrado aos debates racialistas que marcaram sua geração (Saad, 2013). Por outro lado, seu intenso investimento na política, como deputado e presidente do estado, lhe permitiu intensificar seus contatos com o governo federal - o que garantiu sua participação na criação do Ministério de Instrução e Saúde, nos debates sobre a necessidade de manicômios judiciários e na Academia Nacional de Medicina do Rio de Janeiro.

O terceiro, Felisbelo Freire, também se formou em 1882 na Faculdade de Medicina da Bahia. Originário de grupo familiar proprietário de um engenho de pequeno a médio porte, retornou a Sergipe logo depois de formado e passou a exercer a medicina em Laranjeiras, um dos principais centros políticos e econômicos da província nesse período. Em seguida inseriu-se no movimento republicano, fundando em 1888 o Manifesto Republicano, alguns jornais e, em seguida, o Partido Republicano. Sua carreira política tem início no movimento republicano junto a seu tio, ao Coronel Baltazar Góis, Josino de Menezes e Fausto Cardoso, elegendo-se presidente do estado no início da República. Contudo, dadas as divisões surgidas no interior do partido, Felisbelo é destituído do cargo por não ter incluído na chapa para senador um político 
prestigiado por Deodoro da Fonseca. Foi deputado federal e ministro dos negócios estrangeiros na presidência de Floriano Peixoto, no período de 22 de abril a 30 de junho de 1893, e também ministro da Fazenda, de 30 de abril de 1893 a 18 de agosto de 1894 (Abreu, 2001; Santana, 2009).

A intensa valorização na diversificação do capital social constitui a marca fundamental das estratégias das parentelas caracterizadas pela extensão das redes de relações. Os investimentos nos títulos e diplomas e na formação dos filhos garantiram um trunfo fundamental convertido facilmente em capital político (mandato de deputado, senador, presidente do estado). A partir do momento em que eles se deslocavam para os grandes centros urbanos, seja para se formarem médicos ou para atuarem na política como senadores ou deputados, ampliavam o capital social das suas famílias promovendo uma valorização dos membros não parentes para as alianças políticas locais.

Apoiando-se nas trajetórias de alguns médicos sergipanos e nas genealogias, procuramos traçar um padrão geral das relações entre família, política e medicina e das práticas sociais e políticas que se estendem até o início do século $\mathrm{XX}$. Tais trajetórias têm como princípio básico as relações sociais firmadas sobre o sistema de parentela, uma vez que é esse sistema que fornece os critérios de recrutamento para a carreira médica. Por essa razão, uma das principais características dessa elite é seu alto grau de segmentação e fragmentação no período. Nesse sentido, "ser médico" era se distinguir dentro de uma parentela, com base na qual era possível ocupar postos públicos e investir numa carreira para a política. Esse padrão de carreira permitiu a entrada desses ofícios na política estatal e o reconhecimento do saber médico para a formação do Estado.

Alguns se limitaram ao âmbito local, restringindo sua atuação ao município e, no máximo, ao estado; outros, entretanto, tornaram-se importantes chefes políticos regionais expandindo suas alianças políticas para fora do estado. Em todo caso, pode-se afirmar que esses médicos têm suas carreiras marcadas pelo inicial e passageiro investimento na clínica médica e, em seguida, pela ocupação dos cargos dominados pelas parentelas e pela indicação dos chefes políticos locais como delegado, chefe de hospitais ou inspetor de higiene, e como consequência a dedicação à carreira política parlamentar no plano estadual. Assim, eles representavam chefes políticos tradicionais, para os quais a medicina exerceu uma força agregada à posição política da família.

Além disso, outro elemento constitutivo desses percursos foi a atuação no plano federal como maneira de as parentelas ampliarem as alianças políticas, diversificando as redes para com isso interferir na política regional com mais força. Num contexto de forte concorrência com os saberes tradicionais 
(curandeiras, benzedeiras) e de intensa atuação na política, esses bacharéis investiram na medicina como estratégia para manter a força de suas parentelas.

\section{CONSIDERAÇÕES FINAIS}

Este estudo trouxe para o primeiro plano de análise o exame da sociogênese do ofício médico com base na relação entre as formas de organização dos grupos dirigentes e as carreiras dos profissionais. O exame de Sergipe procurou trazer como contribuição à literatura acadêmica que o título de médico não se constituiu apenas como um título simbólico de prestígio político, já que na prática a maioria não exercia o ofício, mas teve papel determinante na expansão do capital social das famílias dirigentes.

A análise permitiu destacar dois conjuntos de questões. O primeiro diz respeito ao padrão de conexão entre as famílias que ocupavam posição dominante no espaço político e econômico e o investimento em títulos acadêmicos. Trata-se, portanto, do papel que a educação universitária e algumas profissões exerceram, sobretudo as liberais, na constituição do espaço político e da reprodução e manutenção da condição de famílias dirigentes. As famílias procuravam garantir aos filhos um diploma que lhes proporcionasse acesso a cargos políticos, viabilizando a sobrevivência política do grupo. Além disso, um filho médico alargava a rede familiar que por sua vez se tornava importante trunfo político nas lutas locais. Dessa forma, o investimento em títulos escolares constitui-se como uma importante estratégia, por um lado, de manutenção da condição de grupo dominante no espaço político e no controle dos postos; por outro, de diversificação dos investimentos das parentelas na política. O processo aqui denominado de “conversão dos títulos" representou um movimento de renovação e recomposição das elites políticas locais.

É, contudo, o caráter extenso das relações familiares dos membros das oligarquias locais que permitiu a reconversão dos títulos em capital político. Isso porque, como mostra Saint-Martin (1995, p.1035), "são os detentores de todo tipo de recurso que têm maior probabilidade de empreenderem uma reconversão". Assim, as possibilidades de reconversão se ampliam para aqueles que diversificam seus recursos. As estratégias familiares que se apoiavam nos filhos, por meio das alianças matrimoniais, dos títulos acadêmicos e das profissões liberais, são dependentes de um sistema aberto de parentesco com capacidade de incluir os de fora para dentro do sistema. Esse sistema aberto, denominado de "sistema de parentela", tornou-se um fenômeno complexo envolvendo a política municipal e uma rede de compromisso, troca e favor. 
O segundo conjunto de questões está associado ao perfil da elite médica e às condições de possibilidades de exercício médico e à forma como os profissionais, inseridos num sistema de dominação de chefes políticos locais, construíram suas carreiras. Dito de outro modo, o caminho possível para aqueles que almejavam a medicina e a respectiva progressão na carreira dependia do investimento em alianças familiares e políticas e da situação em que se encontravam tais relações e vínculos constitutivos da parentela. Apesar de constituir uma elite homogênea, em termos de origens sociais, espaços de consagração e treinamento, era ao mesmo tempo uma elite fragmentada, uma vez que os médicos estavam distribuídos em parentelas, muitas vezes, concorrentes.

Portanto, esse conjunto de questões que servem de conclusão permite demonstrar a pertinência de uma gênese social das profissões que não ignore os processos históricos particulares e, no caso específico das profissões dominantes, como a medicina, coloque em evidência a formação e configuração de suas elites.

\section{REFERENNCIAS}

ABREU, Alzira A. de. Dicionário Histórico Biográfico Brasileiro. Rio de Janeiro: CPDOC/Ed. FGV, 2001.

ADORNO, Sérgio. Os aprendizes do poder: o bacharelismo liberal na política brasileira. Rio de Janeiro: Paz e Terra, 1988.

ALBUQUERQUE, Samuel B. de Medeiros. Aspectos do Baronato Sergipano (18481889). Revista do Instituto Histórico Geográfico de Sergipe, n.22, p.105-127, 2002.

BECKER, Howard S. Boys in white: student culture in medical school. Chicago: The University of Chicago Press, 1961.

BLONDEL, Jean. As condições sociais da vida política na Paraíba. Rio de Janeiro: Ed. FGV, 1957.

BOCHNER, Rosany; MOREIRA, Marcelo. Teses de Doutoramento da Faculdade de Medicina da Bahia produzidas entre 1853 e 1935: principais temáticas e problemas de saúde pública. In: ENCONTRO NACIONAL DE PESQUISA EM CIÊNCIA DA INFORMAÇÃO (ENANCIB), 16. João Pessoa: Ancib, 2015.

BORGES, Dain Edward. The Family in Bahia, Brazil 1870-1945. Palo Alto, CA: Stanford University Press, 1992.

BOURDIEU, Pierre. La Noblesse d'État: grandes écoles et esprit de corps. Paris: Éd. de Minuit, 1989.

CANDIDO, Antonio. The Brazilian Family. In: SMITH, T. Lynn; MARCHANT, Alexander (Ed.) Brazil, portrait of a continent. New York: The Dryden Press, 1951. 
CANEDO, Letícia B. Um capital político multiplicado no trabalho genealógico. Revista Pós Ciências Sociais, São Luís: UFMA, v.8, n.15, jan./jun. 2011.

CARVALHO, José Murilo de. A construção da ordem: a elite política imperial. 3.ed. Rio de Janeiro: Civilização Brasileira, 2007.

CHALHOUB, Sidney. Cidade febril. São Paulo: Companhia das Letras, 1996.

CHARLE, Christophe. Como anda a história social das elites e da burguesia? Tentativa de balance crítico da historiografia contemporânea. In: HEINZ, Flávio (Org.) Por outra história das elites. Rio de Janeiro: Ed. FGV, 2006. p.18-39.

CORADINI, Odacir L. As elites como objeto de estudos. In: Estudos de Grupos Dirigentes no Rio Grande do Sul: algumas contribuições recentes. Porto Alegre: Ed. UFRGS, 2008. p.7-18.

. Grandes famílias e "elite profissional" na medicina no Brasil. História, Ciências, Saúde - Manguinhos, Rio de Janeiro, v.3, n.3, p.425-466, 1996.

DANTAS, Ibarê. História de Sergipe República (1889-2000). Rio de Janeiro: Tempo Brasileiro, 2004.

. Leandro Ribeiro de Siqueira Maciel: o patriarca do Serra Negra e a política oitocentista em Sergipe (1825-1909). Aracaju: Criação, 2009.

DEZALAY, Yves; GARTH, Bryant. A construção jurídica de uma política de notáveis: o jogo duplo da elite do judiciário indiano no mercado de virtude cívica. Revista Pós Ciências Sociais, São Luís: UFMA, v.12, n.23, p.37-59, 2015.

DULONG, Delphine. Quand l'économie devient politique: la conversion de la compétence économique en compétence politique sous la Ve République. Politix, v.35, p.109-135, 1996.

EDLER, Flávio. A Escola Tropicalista Baiana: um mito de origem da Medicina Tropical no Brasil. História, Ciência, Saúde - Manguinhos, Rio de Janeiro, v.9, n.2, p.357385, maio/ago. 2002.

. A Medicina Brasileira no Século XIX: um balanço historiográfico. Asclepio, v.L-2, p.169-186, 1998.

FREIDSON, Eliot. Profissão Médica: um estudo da sociologia do conhecimento aplicado. São Paulo: Ed. Unesp, 2009.

FREYRE, Gilberto. Sobrados e mucambos. São Paulo: Global, 2003.

GRILL, Igor G. Especialização política: bases sociais, profissionalização e configurações de apoios. In: SEIDL, Ernesto; GRILL, Igor G. (Org.) As Ciências Sociais e o espaço da política no Brasil. Rio de Janeiro: Ed. FGV, 2013. p.103-140.

GUARANÁ, Armindo. Dicionário Bio-bibligráfico Sergipano. Rio de Janeiro: Ponghetti, 1925.

HOLANDA, Sérgio B. de. Raizes do Brasil. São Paulo: Companhia das Letras, 2016.

HUGHES, Everett C. The making of a physician: general statement of ideas and problems. Human Organization, v.14, n.4, p.21-25, 1956. 
KARADY, Victor. A conversão socioprofissional das elites: dois casos históricos na Hungria. Revista Pós Ciências Sociais, São Luís: UFMA, v.12, n.23, p.19-36, 2015. LEAL, Victor N. Coronelismo, enxada e voto. Rio de Janeiro: Forense, 1949.

LEVINE, Robert E. Pernambuco e a Federação Brasileira. In: FAUSTO, Boris et al. História Geral da Civilização Brasileira (1889-1930). Rio de Janeiro: Bertrand Brasil, 2006. p.130-171.

LEWIN, Linda. Política e parentela na Paraíba: um estudo de caso da oligarquia de base familiar. Rio de Janeiro: Record, 1993.

LOVE, Joseph. O Rio Grande do Sul como fator de instabilidade na República Velha. In: FAUSTO, Boris et al. História Geral da Civilização Brasileira (1889-1930). Rio de Janeiro: Bertrand Brasil, 2006. p.111-138.

.; BARICKMAN, Bert J. Elites regionais. In: HEINZ, Flávio (Org.) Por outra história das elites. Rio de Janeiro: Ed. FGV, 2006. p.77-98.

LUZ, Madel T. A arte de curar versus a ciência das doenças: história social da homeopatia no Brasil. São Paulo: Dynamis, 1996.

NASCIMENTO, Sayonara R. do. Representação da Reação Republicana em Sergipe: a campanha oposicionista do Jornal do Povo ao governo Pereira Lobo (1921-1922). Revista do Instituto Histórico de Sergipe, Aracaju, n.36, p.109-134, 2007.

OFFERLÉ, Michel. Professions et Profession Politique. In: (Dir.) La profession politique: XIXe siècle. Paris: Belin, 1999. p.7-36.

OLIVEIRA, Vanessa dos S. Conflitos internos em Sergipe: a instabilidade política e a consolidação da autonomia (1824). Revista do Instituto Histórico Geográfico de Sergipe, Aracaju, n.34, p.75-102, 2005.

OLIVEIRA, Wilson José F. de. Engajamento político, competência e elites dirigentes do movimento ambientalista. Revista de Sociologia e Política, Curitiba: UFPR, v.16, p.167-186, 2008.

PANG, E. S. Coronelismo e oligarquia (1889-1943): a Bahia na Primeira República. Rio de Janeiro: Civilização Brasileira, 1979.

PETRARCA, Fernanda R. Esfera política e processos de consolidação dos saberes profissionais. In: SEIDL, Ernesto; GRILL, Igor G. (Org.) As Ciências Sociais e o espaço da política no Brasil. Rio de Janeiro: Ed. FGV, 2013. p.103-140.

.; REIS, E. T. Profissões e o espaço da política: potencialidades de uma agenda de pesquisa. Revista Pós Ciências Sociais, São Luís: UFMA, v.12, n.23, p.11-18, 2015.

QUEIROZ, Maria Isaura P. de. Contribuição para o estudo da sociologia política no Brasil. In: . O mandonismo local na vida política brasileira e outros ensaios. São Paulo: Alfa-Omega, 1976. p.17-43.

. Coronelismo numa interpretação sociológica. In: FAUSTO, B. et al. História da Civilização Brasileira. Rio de Janeiro: Bertrand Brasil, 2006. p.172-214. 
SAAD, Luísa G. Fumo de negro: a criminalização da maconha no Brasil (1890-1932). Dissertação (Mestrado) - Faculdade de Filosofia e Ciências Humanas, Universidade Federal da Bahia (UFBA). Salvador, 2013.

SAINT-MARTIN, Monique de. Une grande famille. Actes de la recherche en Sciences Sociales, n.31, p.4-21, 1980.

. Reconversões e reestructurações das elites: o caso da aristocracia em França. Análise social, Lisboa: Instituto de Ciências Sociais da Universidade de Lisboa, v.XXX, n.134, p.1023-1039, 1995.

SANTANA, Antônio S. Dicionário Biográfico de Médicos de Sergipe: séculos XIX e XX. Aracaju: Academia Sergipana de Medicina, 2009.

. As febres do Aracaju: dos miasmas aos micróbios. Aracaju: O Autor, 2001.

SANTOS, Laura C. dos. Práticas de cura e terapeutas populares em Salvador no início do século XIX. In: ENCONTRO ESTADUAL DE HISTÓRIA, 3. Poder, Cultura e Diversidade. Caetité, 2006. Anais eletrônicos... Caetité: Uneb, 2007. Disponível em: http://www.uesb.br/anpuhba/default.asp?site=artigos/anpuh_III/anais.html.

SANTOS NETO, Amâncio C. dos. Sob o signo da peste: Sergipe em tempos de cólera (1855-1856). Dissertação (Mestrado) - Instituto de Filosofia e Ciências Humanas (IFCH), Universidade Estadual de Campinas (Unicamp). Campinas, 2001.

VIANNA, Francisco J. de Oliveira. Instituições Políticas Brasileiras. Brasília: Senado Federal, 1999.

\section{NOTAS}

${ }^{1}$ Mestre (2003) e Doutora (2007) em Sociologia pela Universidade Federal do Rio Grande do Sul (UFRGS). Pós-doutora e Professora Adjunta, Universidade Federal de Sergipe (UFS).

2 Dentre esses estudos podemos citar: CORADINI, 1996; DULONG, 1996; DEZALAY; GARTH, 2015; KARADY, 2015; LOVE; BARICKMAN, 2006; OFFERLÉ, 1999; OLIVEIRA, 2008; PETRARCA, 2013; GRILL, 2013; PETRARCA; REIS, 2015; SAINT-MARTIN, 1980.

${ }^{3}$ Essa definição tem como ponto de partida central os estudos sobre elites e grupos dirigentes empreendidos, sobretudo, por CHARLE (2006) e BOURDIEU (1989), os quais consideram o acesso a posições privilegiadas como parte das estruturas de dominação.

${ }^{4}$ Este estudo faz parte de uma pesquisa mais ampla sobre os processos de recrutamento, os princípios e critérios de seleção, bem como as modalidades de ascensão profissional na medicina em Sergipe. A pesquisa contou com financiamento do CNPq e da Capes, aos quais agradecemos por nos oferecer as condições materiais de realização deste trabalho.

${ }^{5}$ Os principais concorrentes dos médicos, no mercado de cura, eram as rezadeiras, as ben- 
zedeiras e os curandeiros que, em geral, tinham mais credibilidade e eram mais procurados pela população (SANTOS, 2007).

${ }^{6} \mathrm{O}$ cargo de senador no período imperial era uma indicação das províncias.

${ }^{7}$ Um dos principais confrontos da medicina nesse contexto era a interpretação das febres, que dividia o círculo dos catedráticos entre a teoria dos miasmas e a teoria do contágio. A primeira sustentava a contaminação através dos meios insalubres, e a segunda buscava explicações etiológicas (EDLER, 1998).

8 "Cabaús" e "Pebas" foram duas grandes facções que surgiram em Sergipe no final do século XIX, decorrentes das mudanças nas relações de força provocadas pela República, e que levaram à constituição de duas fortes lideranças: Olimpio Campos e Valladão. De um lado, os "cabaús", que se reuniam na região canavieira e representavam os senhores de engenho; de outro, os "pebas", ligados aos grupos e lideranças locais republicanas que se reuniam em Aracaju (DANTAS, 2009).

Artigo recebido em 24 de fevereiro de 2016. Aprovado em 17 de novembro de 2016. 